\title{
PENGARUH STRES KERJA TERHADAP TURNOVER INTENTION MELALUI MEDIASI KOMITMEN ORGANISASIONAL PADA RESTORAN QUEEN'S TANDOOR SEMINYAK
}

\author{
Gede Dirga Pranata ${ }^{1}$ \\ I Gusti Salit Ketut Netra ${ }^{2}$
}

${ }^{1,2}$ Fakultas Ekonomi dan Bisnis Universitas Udayana (Unud), Bali, Indonesia E-mail:dirgapranataa@gmail.com

\begin{abstract}
ABSTRAK
Tujuan dari penelitian ini adalah untuk menjelaskan pengaruh stres kerja terhadap turnover intention melalui mediasi komitmen organisasional. Penelitian ini dilakukan di restoran Queen's Tandoor Seminyak di Kabupaten Badung. Jumlah sampel dalam penelitian ini sebanyak 79 orang karyawan, melalui metode nonprobability sampling, khususnya sampel jenuh. Pengumpulan data dilakukan melalui penyebaran kuesioner, wawancara, dan observasi. Teknik analisis yang digunakan adalah analisis jalur (path analysis). Berdasarkan hasil penelitian ditemukan bahwa stres kerja berpengaruh positif dan signifikan terhadap turnover intention. Stres kerja berpengaruh negatif dan signifikan terhadap komitmen organisasional. Komitmen organisasional berpengaruh negatif dan signifikan terhadap turnover intention. Komitmen organisasional dapat memediasi pengaruh stres kerja terhadap turnover intention. Manajemen sebaiknya memperhatikan pembebanan pekerjaan agar tidak melebihi kemampuan karyawan yang dapat mengakibatkan stres kerja dan meningkatkan keterlibatan karyawan di dalam perusahaan.

Kata kunci:stres kerja, komitmen organisasional, turnover intention
\end{abstract}

\begin{abstract}
The purpose of this study is to explain the effect of work stress on turnover intention through the mediation of organizational commitment. This research was conducted at the Queen's Tandoor Seminyak restaurant in Badung Regency. The number of samples in this study were 79 employees, through the nonprobability sampling method, especially saturated samples. Data collection is done through distributing questionnaires, interviews, and observations. The analysis technique used is path analysis. Based on the results of the study found that work stress has a positive and significant effect on turnover intention. Job stress has a negative and significant effect on organizational commitment. Organizational commitment has a negative and significant effect on turnover intention. Organizational commitment can mediate the effect of work stress on turnover intention. Management should pay attention to the imposition of work so as not to exceed the ability of employees who can lead to job stress and increase employee involvement in the company.

Keywords: work stress, organizational commitment, turnover intention
\end{abstract}




\section{PENDAHULUAN}

Sumber Daya Manusia (SDM) merupakan salah satu faktor penentu dibalik kesuksesan suatu organisasi atau perusahaan dalam mencapai tujuannya. Dewasa ini, SDM yang sangat dibutuhkan oleh perusahaan adalah yang mudah berdaptasi, cakap, memiliki komitmen yang kuat terhadap organisasi, memiliki inisiatif yang tinggi, mentaati peraturan yang berlaku, serta mampu menyelesaikan tugas yang diberikan oleh atasan dengan semaksimal mungkin. SDM yang berkualitas serta pelatihan dan pengelolaan SDM yang baik akan memberikan dampak positif bagi kemajuan organisasi atau perusahaan tempatnya berkerja.

Dewasa ini, mencari SDM yang berkualitas tidaklah mudah ditemukan, maka dari itu sebaiknya perusahaan yang sudah memiliki SDM yang berkompeten harus dijaga kinerjanya agar selalu stabil dan terus meningkat. SDM yang handal merupakan sebuah aset penting bagi perusahaan guna mencapai visi dan misi dari perusahaan tersebut. Oleh karena itu, SDM harus dilatih dan dikembangkan kemampuannya semaksimal mungkin sebagai upaya untuk meningkatkan kinerja. Dalam hal ini, SDM diharapkan untuk dapat memberikan kontrbusi yang optimal guna pencapaian tujuan perusahaan yang efektif dan efisien. Untuk dapat mengelola SDM dengan baik, setiap pemimpin dan manajer serta bagian yang mengenai SDM harus mengerti masalah manajemen dengan baik pula (Widodo, 2015). Di dalam sebuah perusahaan perlu adanya pengelolaan SDM sebaik mungkin agar dapat terwujudnya keseimbangan antara kebutuhan dan kemampuan karyawan dengan tuntutan dari perusahaan.

Salah satu bentuk perilaku karyawan yang sering muncul akibat kegagalan perusahaan mengelola SDM yang dimilikinya adalah keinginan untuk berpindah 
kerja (turnover intention) yang mengakibatkan keputusan karyawan untuk meninggalkan pekerjaannya.Turnover Intention merupakan keinginan karyawan untuk meninggalkan perusahaan, sikap emosional karyawan akan berpengaruh terhadap intensi keluar (Green et al., 2013).Saat karyawan meninggalkan perusahaan, kemampuan karyawan lainnya untuk menyelesaikan pekerjaan yang ada akan terganggu (Fah et al., 2010). Dengan demikian jelas bahwa turnover akan berdampak negatif bagi organisasi karena menciptakan ketidakstabilan terhadap kondisi tenaga kerja, menurunnya produktifitas karyawan, suasana kerja yang tidak kondusif dan juga berdampak pada meningkatnya biaya SDM (Widodo, 2015). Turnover tinggi dikatakan dapat meningkatkan biaya SDM karena perusahaan akan mengeluarkan biaya dan waktu tambahan untuk melakukan proses rekrutmen, seleksi karyawan baru dan pelatihan karyawan. Selain itu, produktifitas perusahaan akan terhambat dan menurun dalam pelaksanaannya dikarenakan kurangnya tenaga kerja akibat dari keluarnya karyawan tersebut dari perusahaan. Johartono dan Widuri (2014) menyebutkan bahwa faktor yang menyebabkan karyawan memiliki keinginan untuk berpindah kerja diantaranya adalah stres kerja, kepuasan kerja, budaya organisasi, dan komitmen organisasional. Namun, dalam penelitian ini hanya mengunakan 2 faktor yang mempengruhi turnover yaitu stres kerja dan komitmen organisasional.

Penyebab terjadinya turnover intention salah satunya adalah stres kerja. Terdapat pengaruh positif antara stres kerja dan turnover intention, hal ini menunjukkanbahwa semakin tinggi tingkat stres kerja yang dialami oleh karyawan maka akan cenderung meningkatkan keinginan mereka untuk 
meninggalkan perusahaan (Rismawan, 2014). Chandio et al. (2013) mengatakan bahwa stres kerja meningkat maka akan menyebabkan timbulnya keinginan keluar yang ada pada diri karyawan. Menurut Sunyoto (2015:54) stres kerja merupakan keadaan dinamik yang mana seseorang dihadapkan pada sebuah peluang, tuntutan, ataupun resource yang berkaitan dengan rasa inginnya orang itu beserta hasil kerjanya dinilai tidak pasti atau penting. Jadi, stres adalah konsekuensi setiap tindakan dan situasi lingkungan yang menimbuklan tuntutan psikologis dan fisik yang berlebihan pada seseorang. Stres yang tidak bisa diatasi dengan baik biasanya berakibat pada ketidakmampuan orang berinteraksi secara positif terhadap lingkungannya, baik lingkungan luar maupun lingkungan dalam (Budiyono, 2016). Jadi, tingginya tingkat stres kerja pada keryawan akan mempengaruhi tingginya tingkat turnover pada organisasi.

Selain stres kerja, penyebab terjadinya turnover intention salah satunya adalah menurunnya komitmen organisasional dari karyawan.Saqib (2014) menunjukkan bahwa komitmen organisasional yang tinggi akan mengakibatkan menurunnya turnover intention karyawan. Jehanzeb et al.(2013) dalam studinya menunjukkan adanya hubungan negatif yang kuat antara komitmen organisasional dengan turnover intention karyawan, jadi semakin tinggi tingkat komitmen organisasional pada karyawan maka semakin rendah terjadinya tingkat turnover intention. Komitmen organisasional dipandang sebagai suatu orientasi nilai terhadap organisasi yang menunjukkan pemikiran individu dan mengutamakan pekerjaan dan organisasinya (Tania dan Sutanto, 2013).Karyawan yang memiliki komitmen yang kuat dapat dilihat dari tingkat absensi yang rendah, meningkatnya 
kinerja karyawan dan adanya keinginan yang kuat untuk bertahan di dalam organisasi tersebut. Karyawan yang berkomitmen sangat dibutuhkan oleh organisasi karena karyawan yang memiliki komitmen yang tinggi akan berusaha semaksimal mungkin untuk mewujudkan visi, misi dan tujuan dari organisasi tempatnya berada. Karyawan dengan komitmen tinggi akan berdampak positif bagi kemajuan organisasi dimana ia berada sehingga karyawan yang memiliki komitmen yang tinggi harus diberikan dukungan dari organisasi agar karyawan tersebut merasa dirinya bermakna di dalam organisasi yang nantinya dapat meningkatkan komitmennya.

Queen's Tandoor Seminyak merupakan restoran yang menyajikan menu otentik khas India. Queen's Tandoor Seminyak merupakan salah satu dari 4 restoran yang dimiliki oleh perusahaan Queen's Of Bali. Keempat restoran itu diantaranya Queen's Tandoor Seminyak, Queen's Of India Kuta, Queen's Of India Nusa Dua dan Queen's Of India Ubud. Namun penelitian ini memfokuskan Queen's Tandoor Seminyak sebagai lokasi penelitian. Dipilihnya Queen's Tandoor Seminyak karena merupakan gerai pertama dari keempat gerai lainnya di Bali, restoran ini pertama kali beroperasi pada tahun 2004. Pra riset yang dilakukan adalah melalui wawancara terhadap dua orang karyawan Queen's Tandoor Seminyak mengenai apakah sering terjadi karyawan yang memilih untuk meninggalkan organisasi. Narasumber menyatakan bahwa hal tersebut cukup sering terjadi bahkan dibeberapa kasus ada karyawan yang baru bekerja sebulan dan memutuskan untuk mengundurkan diri. 
Meskipun sudah beroperasi lebih dari 10 tahun, namun sama halnya dengan restoran lainnya, Queen's Tandoor Seminyak juga tidak luput dari berbagai permasalahan yang terkait dengan karyawan, salah satunya adalah masalah mengenai turnover. Hal tersebut terlihat dari seringnya terjadi perputaran karyawan pada restoran ini. Berikut ini adalah data turnover karyawan pada Queen's Tandoor Seminyak.

Tabel 1.

Data Turnover Queen's Tandoor Seminyak Periode 2017 - 2018

\begin{tabular}{|c|c|c|c|c|c|c|c|c|c|}
\hline \multirow{2}{*}{ Bulan } & \multirow{2}{*}{$\begin{array}{l}\text { Kar. } \\
\text { Keluar }\end{array}$} & \multicolumn{2}{|c|}{$\begin{array}{c}\text { J. } \\
\text { Kelamin }\end{array}$} & \multicolumn{5}{|c|}{ Satuan Kerja } & \multirow{2}{*}{$\begin{array}{c}\text { Kar. } \\
\text { Masuk }\end{array}$} \\
\hline & & $\mathbf{L}$ & $\mathbf{P}$ & Adm & Cen & Drv & Kitc & Serv & \\
\hline Jan '17 & 3 & 3 & - & 1 & 1 & 1 & - & - & 2 \\
\hline Feb ‘17 & 4 & 3 & 1 & 1 & - & - & 1 & 2 & 4 \\
\hline Mar ‘17 & 13 & 11 & 2 & 3 & 7 & - & 1 & 2 & 11 \\
\hline Apr '17 & 1 & 1 & - & - & - & - & 1 & - & 1 \\
\hline Mei '17 & 7 & 6 & 1 & 1 & - & - & - & 6 & 6 \\
\hline Jun`17 & - & - & - & - & - & - & - & - & - \\
\hline Jul ‘ 17 & - & - & - & - & - & - & - & - & - \\
\hline Agu ‘17 & - & - & - & - & - & - & - & - & 1 \\
\hline Sep '17 & 15 & 11 & 4 & 6 & 2 & - & 1 & 6 & 16 \\
\hline Okt '17 & 1 & 1 & - & - & - & 1 & - & - & 3 \\
\hline Nov '17 & 1 & - & 1 & - & 1 & - & - & - & 2 \\
\hline Des ‘'17 & - & - & - & - & - & - & - & - & - \\
\hline Jan '18 & - & - & - & - & - & - & - & - & - \\
\hline Feb '18 & 1 & 1 & - & 1 & - & - & - & - & - \\
\hline Mar '18 & 3 & 2 & 1 & 1 & - & - & 2 & - & 2 \\
\hline Apr '18 & 1 & - & 1 & 1 & - & - & - & - & - \\
\hline Jumlah & 50 & & & & & & & & 48 \\
\hline
\end{tabular}

Sumber: HRD Queen's Tandoor Seminyak, 2018

Data turnover pada Tabel 1 dapat dilihat bahwa Queen's Tandoor Seminyak memiliki jumlah karyawan keluar berdasarkan jenis kelamin, laki-laki sebanyak 39 orang dan perempuan sebanyak 11 orang. Lalu menurut satuan kerja, karawan keluar didominasi oleh bagian service sebanyak 16 orang, admin sebanyak 15 orang, central sebanyak 11 orang, kitchen 6 orang dan yang paling sedikit driver sebanyak 2 orang. 
Dilihat dari jumlah karyawan yang keluar, maka turnover pada Queen's Tandoor Seminyak pada periode 2017-2018 cenderung tinggi, hal ini dibuktikan dengan jumlah total karyawan yang keluar sebanyak 50 orang dan karyawan masuk sebanyak 48 orang. Menurut pihak HRD yang saya temui, penyebab dari tingginya turnover yang terjadi dikarenakan beban kerja yang dirasa berat, serta keinginan dari karyawan untuk mencari pekerjaan di organisasi lain yang dirasa lebih baik dari pekerjaannya yang sekarang. Stres kerja karyawan dapat meningkatkan turnover intention. Stres kerja yang tinggi akan berdampak pada individu dan organisasi tempatnya bekerja, tiap individu memiliki pandangan berbeda mengenai stres kerja yang dirasakannya. Beberapa individu menganggap stres kerja merupakan hal yang biasa saat bekerja sehingga mereka tidak langsung berfikir untuk keluar dari organisasi saat mengalami stres kerja, namun ada pula individu yang menganggap sebaliknya mereka akan langsung meninggalkan organisasinya saat mereka mengalami stres kerja di organisasi tersebut. Penelitian sebelumnya yang dilakukan oleh Firth et al.(2004) mengemukakan bahwa karyawan dengan stres kerja tinggi akan berdampak pada rendahnya komitmen organisasi. Komitmen organisasional memediasi hubungan antara stes kerja dengan intensi keluar karyawan.

Turnover intention merupakan suatu keadaan dimana pekerja memiliki niat atau kecenderungan yang dilakukan secara sadar untuk mencari pekerjaan lain sebagai alternatif di organisasi yang berbeda (Abdullah et al., 2012). Keinginan keluar (turnover intention) juga bisa dikatakan sebagai pergerakan karyawan untuk keluar dari perusahaannya untuk mendapatkan pekerjaan baru di perusahaan 
lain. Dampak negatif turnover adalah dampak terhadap biaya organisasi yang berkaitan dengan rekrutmen, seleksi, serta pelatihan personil baru, ditambah lagi turnover dapat menyebabkan penurunan efektivitas dan produktivitas kinerja karyawan karena telah kehilangan rekan kerjanya (Jha, 2010).

Bila turnover terjadi pada pekerja yang tidak berpengaruh besar terhadap perusahaan dan tidak produktif bisa disebut turnover fungsional, sedangkan turnover yang terjadi pada karyawan yang potensial dan berpengaruh besar terhadap perusahaan disebut turnover disfungsional (Sidharta dan Margaretha, 2011). Turnover Intention timbul dari niat yang mengacu pada aktivitas karyawan untuk meninggalkan perusahaan dan mencari alternatif pekerjaan yang lain (Faslah, 2017). Tindakan seperti itu dapat menyebabkan karyawan yang berkompeten akan meninggalkan perusahaan.

Salah satu masalah yang dihadapi oleh setiap orang dalam kehidupan kerja adalah stres yang harus diatasi, baik oleh karyawan sendiri tanpa bantuan orang lain, maupun dengan bantuan pihak lain seperti para spesialis yang disediakan oleh organisasi dimana karyawan bekerja (Siagian, 2012:300). Robbins and Judge (2015:433) mendefinisikan stres sebagai suatu proses psikologis yang tidak menyenangkan yang terjadi sebagai tanggapan terhadap tekanan lingkungan. Stres kerja merupakan persepsi karyawan terhadap tuntutan pekerjaan dibandingkan dengan persepsi kendali terhadap pekerjaan tersebut (Udayana dan Dewi, 2017).

Robbins dan Judge (2015:84) mendefinisikan komitmen organisasi sebagai suatu keadaan karyawan memihak kepada perusahaan tertentu dan tujuan tujuannya, serta berniat memelihara keanggotaannya dalam perusahaan itu. 
Komitmen organisasional dapat dikatakan memiliki dampak yang signifikan terhadap keinginan karyawan untuk meninggalkan organisasi (Khan et al., 2014). Komitmen organisasional dipandang sebagai suatu orientasi nilai terhadap organisasi yang menunjukkan pemikiran individu dan mengutamakan pekerjaan dan organisasinya (Tania dan Sutanto, 2013). Karyawan-karyawan yang merasa lebih berkomitmen pada organisasi memiliki kebiasaan yang bisa diandalkan, berencana untuk tinggal lebih lama di dalam organisasi dan mencurahkan lebih banyak upaya dalam bekerja. Komitmen organisasional merupakan keadaan psikologis seorang karyawan yang dapat dilihat dari rasa loyalitas karyawan serta mampu fokus terhadap tujuan yang telah ditetapkan oleh organisasi (Crow et al., 2012).

Beberapa penelitian sebelumnya telah membuktikan bahwa stres kerja berpengaruh terhadap turnover intention. Hasil penelitian yangmenguji hubungan stres kerja dengan intensi keluar oleh Rai (2015) menyatakan bahwa stres kerja secara signifikan mempengaruhi intensi keluar, dimana ketika karyawan memiliki tingkat stress kerja yang semakin tinggi maka intensi keluar pada perusahaan juga akan semakin meningkat. Penelitian Siddiqui and Jamil (2015), Ketabchi and Hazraty (2015) membuktikan bahwa stres kerja mempunyai pengaruh positif terhadap turnover intention, semakin tinggi stres kerja pada karyawan maka turnover intention karyawan akan semakin tinggi juga. Salah satu dampak stres kerja yang dialami oleh karyawan adalah munculnya niat untuk berpindah dari pekerjaannya (Manurung dan Ratnawati, 2012), dimana semakin tinggi stres kerja yang dialami karyawan akan meningkatkan turnover intention. Penelitian Parvaiz 
et al.(2015) juga menunjukan stres kerja memiliki hubungan positif dan signifikan dengan turnover intention. Jika karyawan mengalami stres kerja dan tidak memiliki mekanisme yang cocok untuk mengatasi stres kerja tersebut, maka akan menimbulkan keinginan karyawan untuk keluar. Hasil penelitian yang dilakukan oleh Paille (2011) mengatakan bila seseorang dalam keadaan stres, kemungkinan orang tersebut menjadi kurang memperhatikan keadaan sosialnya dan kurang sensitif tehadap orang lain. Hal ini akan menyebabkan ketidak harmonisan dalam hubungan antar karyawan. Interaksi yang kurang harmonis dapat menjadi penyebab karyawan merasa tidak nyaman berada di tempat kerja, sehingga karyawan merasa ingin meninggalkan perusahaan.

Berdasarkan dari penelitian-penelitian diatas, maka dapat diajukan hipotesis sebagai berikut:

$\mathrm{H}_{1}$ : Stres kerja berpengaruh positif dan signifikan terhadap turnover intention.

Nursyamsi (2012:12) dalam penelitiannya menyimpulkan bahwa hubungan antara stres kerja dan komitmen organisasional menunjukkan arah hubungan yang negatif dimana semakin besar stres kerja akan berakibat pada kinerja dan komitmen yang menurun atau berkurang. Firth et al. (2004) menyatakan hubungan negatif antara stres kerja dengan komitmen organisasional, karyawan yang memiliki tingkat stres tinggi berimplikasi terhadap rendahnya komitmen organisasional mereka. Velnampy dan Aravinthan (2013) mengatakan stres kerja memiliki pengaruh negatif dengan komitmen organisasional. Hal ini bermakna bahwa stres kerja yang dialami oleh karyawan dapat mempengaruhi persepsi mereka terhadap keselarasan antara tujuan dan nilai individu dengan organisasi. Rismawan (2014) dan Irwanto dkk. (2016) mengungkapkan hal yang sama yaitu 
stres kerja berpengaruh negatif dan signifikan terhadap komitmen organisasional. Bedasarkan dari dari penelitian-penelitian diatas, maka dapat diajukan hipotesis sebagai berikut:

$\mathrm{H}_{2}$ : Stres kerja berpengaruh negatif terhadap komitmen organisasional

Sebelumnya tentang komitmen dan niat berpindah pekerjaan telah dibuktikan oleh Matti (2014), yang berpendapat bahwa komitmen organisasional terhadap niat berpindah dari pekerjaan memiliki hubungan yang negatif dan signifikan. Kumar et al. (2012); Qureshi (2013) dan Velnamphy et al., (2013) dalam penelitian mereka diketahui bahwa komitmen organisasional terhadap turnover intention berpengaruh negatif dan signifikan. Johartono dan Widuri (2014), serta Putra dan Wibawa (2014) menemukan komitmen organisasi terhadap intensi keluar karyawan yang dapat diartikan semakin tinggi tingkat komitmen organisasi memang berpengaruh negatif signifikan yang dirasakan oleh karyawan maka akan semakin rendah tingkat turnover intention yang akan terjadi.

Bedasarkan dari dari penelitian-penelitian diatas, maka dapat diajukan hipotesis sebagai berikut:

$\mathrm{H}_{3}$ : Komitmen Organisasional berpengaruh negatif terhadap turnover intention.

Rismawandkk. (2014) membuktikan bahwa stres kerja terhadap turnover intention dimediasi oleh komitmen organisasional. Karyawan dengan stres kerja tinggi akan berdampak pada rendahnya komitmen organisasi, komitmen organisasional memediasi hubungan antara stes kerja dengan intensi keluar karyawann (Firth et al., 2004) . 
Bedasarkan dari dari penelitian-penelitian diatas, maka dapat diajukan hipotesis sebagai berikut:

$\mathrm{H}_{4}$ : Komitmen Organisasional mampu memediasi pengaruh stres kerja terhadap turnover intention.

\section{METODE PENELITIAN}

Penelitian ini dilakukan pada restoran Queen's Tandoor Seminyak yang beralamat di Jalan Raya Seminyak, No 1/73, Kuta Selatan. Dipilihnya lokasi ini dikarenakan Queen's Tandoor Seminyak merupakan restoran pertama yang didirikan dari keempat restoran milik perusahaan Queen's Of Bali.

Populasi dalam penelitian ini adalah seluruh karyawan pada Queen's Tandoor Seminyak yaitu sebesar 79 orang. Sampel yang diambil dalam penelitian yaitu sebanyak 79 karyawan. Metode penentuan sampel yang digunakan dalam penelitian ini adalah sampling jenuh, dimana semua anggota populasi dijadikan sampel.

Penelitian ini menggunakan teknik analisis jalur atau path analysis. Analisis jalur (path analysis) adalah perluasan dari analisis regresi linier berganda, dimana pengembangan disini berupa penerapan variabel mediasi. Variabel mediasi merupakan variabel yang memiliki peran memediasi hubungan antara suatu variabel dengan variabel lainnya.

Persamaan Sub-struktural 1

$$
\mathrm{M}=\beta_{1} \mathrm{X}+\mathrm{e}_{1}
$$

Persamaan Sub-struktural 2

$$
\mathrm{Y}=\beta_{1} \mathrm{X}+\beta_{1} \mathrm{M}+\mathrm{e}_{2}
$$

Keterangan: 


$$
\begin{array}{ll}
\mathrm{X} & =\text { Stres Kerja } \\
\mathrm{M} & =\text { Komitmen Organisasional } \\
\mathrm{Y} & =\text { Turnover Intention } \\
\beta_{1-} \beta_{2} & =\text { Koefisien regresi variabel } \\
\mathrm{e} & =\text { error }
\end{array}
$$

Pengujian hipotesis mediasi dapat dilakukan dengan Uji Sobel (Sobel Test). Uji sobel digunakan untuk menguji kekuatan pengaruh tidak langsung variabel stres kerja (X) ke variabel turover intention (Y) melalui variabel komitmen organisasional(M). Pengaruh tidak langsung stres kerja (X) terhadap variabel turnover intention (Y) melalui variabel komitmen organisasional(M) dihitung dengan mengalikan koefisien jalur $\mathrm{X}$ terhadap $\mathrm{M}$ (a) dengan koefisien jalur $\mathrm{M}$ terhadap Y (b) atau ab. Standard error koefisien a dan b ditulis dengan $S_{a}$ dan $S_{b}$, besarnya standard error tidak langsung (indirect effect) $\mathrm{S}_{\mathrm{ab}}$. dihitung dengan rumus dibawah ini:

$$
S=\sqrt{b^{2} S^{2}+u^{2} S^{2}+S^{2} S^{2}}
$$

Keterangan:

$\mathrm{S}_{\mathrm{ab}}$ :Standard error tidak langsung (indirect effect)

$\mathrm{S}_{\mathrm{a}}:$ Standard error koefisien a

$\mathrm{S}_{\mathrm{b}}:$ Standard error koefisien $\mathrm{b}$

Cara menguji signifikansi pengaruh tidak langsung, maka dapat dilakukan dengan menghitung t dari koefisien ab dengan rumus sebagai berikut:

$$
\mathrm{Z}=\frac{a}{\mathrm{~S}}
$$

Pengambilan pada keputusan uji hipotesa, maka dilakukan dengan cara membandingkan p- value dan alpha $(0,05)$ atau membandingkan hitung dengan $\mathrm{z}$ 
tabel, yang menggunakan taraf nyata 5 persen dengan daerah kritis 1,96 dengan ketenuan sebagai berikut:

$\mathrm{Z}$ hitung $\leq \mathrm{Z}$ tabel, maka $\mathrm{H}_{0}$ diterima yang berarti komitmen organisasional bukan sebagai variabel mediasi. Kemudian, jika $\mathrm{Z}$ hitung $\geq \mathrm{Z}$ tabel, maka $\mathrm{H}_{0}$ ditolak yang berarti komitmen organisasional merupakan variabel mediasi.

\section{HASIL DAN PEMBAHASAN}

Penelitian ini menggunakan data primer dari kuesioner yang dijawab oleh para responden yaitu sebanyak 79 orang karyawan Queen's Tandoor Seminyak. Sebaran data karakteristik responden dikumpulkan untuk mengetahui profil responden penelitian. Berdasarkan hasil penelitian yang dilakukan, telah diketahui karakteristik responden meliputi jenis kelamin, usia, dan pendidikan terakhir. Data mengenai karakteristik responden disajikan pada Tabel 2.

Tabel 2.

Karakteristik Responden Penelitian

\begin{tabular}{lcccc}
\hline No. & Kriteria & Klasifikasi & $\begin{array}{c}\text { Jumlah } \\
\text { (Orang) }\end{array}$ & $\begin{array}{c}\text { Persentase } \\
(\mathbf{\%})\end{array}$ \\
\hline 1. & Jenis Kelamin & Pria & 53 & 67,1 \\
& & Wanita & 26 & 32,9 \\
& & 79 & 100 \\
2. & Jumlah & 15 & 19,0 \\
& $18-20$ tahun & 19 & 24,0 \\
& $21-25$ tahun & 16 & 20,2 \\
& Usia & 26-30 tahun & 14 & 17,7 \\
& $31-35$ tahun & 7 & 8,9 \\
& 36-40 tahun & 3 & 3,8 \\
& $41-45$ tahun & 2 & 2,5 \\
& $46-50$ tahun & 3 & 3,8 \\
& 51-55 tahun & 79 & 100 \\
& & 8 & 10,0 \\
& Pendidikan & Jum & 46 & 58,2 \\
& Terakhir & SMA/SMK & 5 & 6,3 \\
& D1 & 6 & 7,6 \\
& D2 & 6 & 7,6 \\
& D3 & 1 & 1,3 \\
& & D4 & 7 & 8,9 \\
& & S1 & 79 & 100 \\
\hline
\end{tabular}

Sumber: Data diolah, 2018 
Tabel 2 menunjukkan hasil sebaran data karakteristik responden pada penelitian ini. Hasil menunjukkan bahwa sebagian besar responden berjenis kelamin pria dengan persentase sebesar $67,1 \%$ dibanding responden wanita sebesar 32,9\%. Hal ini dapat berarti sebagian besar pekerjaan di Queen's Tandoor Seminyak membutuhkan tenaga pria untuk menyelesaikannya. Kelompok usia responden yang mendominasi adalah usia produktif dengan rentang usia terbanyak yakni 21-25 tahun yang memperoleh persentase sebesar $24 \%$. Sementara itu, responden dengan pendidikan terakhir SMA/SMK mendapatkan persentase terbanyak dibandingkan tingkat pendidikan yang lain yaitu sebesar 58,2\%. Hal ini dapat berarti bahwa para karyawan Queen's Tandoor Seminyak sebagian besar tidak menempuh pendidikan tinggi.

Perhitungan koefisien analisis jalur dilakukan dengan analisis regresi melalui software IBM SPSS Statistics 20.0 memperoleh hasil yang ditunjukkan pada Tabel 3 dan Tabel 4.

Tabel 3.

Hasil Analisis Jalur Persamaan Regresi 1 (Stres Kerja terhadap Komitmen Organisasional)

\begin{tabular}{cccc}
\hline Model & R Square & $\begin{array}{c}\text { Standardized Coefficients } \\
\text { Beta }\end{array}$ & Sig. \\
\hline Stres Kerja & 0,243 & $-0,373$ & 0,008 \\
\hline
\end{tabular}

Sumber:Data diolah, 2018

Berdasarkan hasil analisis jalur substruktural 1 yang disajikan pada Tabel

3, maka persamaan strukturalnya adalah:

$$
\begin{aligned}
& M=\beta_{2} X+e \quad \ldots . \\
& M=-0,373 X+e_{1}
\end{aligned}
$$


Tabel 4.

Hasil Analisis Jalur Persamaan Regresi 2 (Stres Kerja dan Komitmen Organisasional terhadap Turnover Intention)

\begin{tabular}{cccc}
\hline & \multicolumn{3}{c}{ Standardized Coefficients } \\
Model & R Square & Beta & Sig. \\
\hline Stres kerja & 0,553 & 0,290 & 0,000 \\
Komitmen Organisasional & & $-0,412$ & 0,004 \\
\hline Sumber: Data diolah, 2018 & &
\end{tabular}

Berdasarkan hasil analisis jalur substruktural 2 yang disajikan pada Tabel 4, maka persamaan strukturalnya adalah:

$$
\begin{aligned}
& \mathrm{Y}=\beta_{1} \mathrm{X}+\beta_{3} \mathrm{M}+\mathrm{e}_{2} \ldots \ldots \\
& \mathrm{Y}=0,290 \mathrm{X}-0,412 \mathrm{M}+\mathrm{e}_{2}
\end{aligned}
$$

Berdasarkan model substruktural 1 dan substruktural 2, maka perhitungan nilai standar eror adalah sebagai berikut:

$$
\begin{aligned}
& \mathrm{ei}=\sqrt{1-\mathrm{Ri}^{2}} \ldots \ldots \ldots \ldots \ldots \ldots \ldots \ldots \ldots \ldots \\
& \mathrm{e}_{1}=\sqrt{1-\mathrm{R}_{1}{ }^{2}}=\sqrt{1-0,243}=0,870 \\
& \mathrm{e}_{2}=\sqrt{1-\mathrm{R}_{2}{ }^{2}}=\sqrt{1-0,553}=0,668
\end{aligned}
$$

Tabel 5.

Hasil Pengujian Nilai Standar Eror

\begin{tabular}{ccc}
\hline Hasil Pengujian & Nilai Standar Eror & Keterangan \\
\hline $\mathrm{e}_{1}$ & 0,870 & Standar eror variabel komitmen organisasional \\
$\mathrm{e}_{2}$ & 0,668 & Standar eror variabel turnover intention \\
\hline Sumber: Data diolah, 2018 & &
\end{tabular}

Berdasarkan perhitungan nilai standar eror, diperoleh hasil $\mathrm{e}_{1}$ atau standar eror variabel komitmen organisasional sebesar 0,870 dan $e_{2}$ atau standar eror variabel turnover intention sebesar 0,668. Perhitungan koefisien determinasi total adalah sebagai berikut:

$$
\begin{aligned}
R^{2} m & =1-\left(e_{1}\right)^{2}\left(e_{2}\right)^{2} \ldots \ldots \ldots \\
& =1-(0,870)^{2}(0,668)^{2}
\end{aligned}
$$




$$
=0,662
$$

Nilai determinasi total sebesar 0,662 mempunyai arti bahwa sebesar 66,2\% variasi turnover intention dipengaruhi oleh variasi stres kerja dan komitmen organisasional, sedangkan sisanya sebesar $33,8 \%$ dipengaruhi oleh faktor lain yang tidak dimasukkan ke dalam model penelitian.

Berdasarkan hasil regresi persaman 2 pada Lampiran 6, diperoleh nilai $\mathrm{F}$ sebesar 19,403 dengan nilai signifikansi 0,000. Oleh karena nilai signifikansi lebih kecil dari $0,05(0,000<0,05)$, maka dapat disimpulkan bahwa $\mathrm{H}_{0}$ ditolak dan $\mathrm{Ha}$ diterima. Dengan demikian, variabel stres kerja dan komitmen organisasional berpengaruh secara simultan dan signifikan terhadap turnover intention.

Berdasarkan hasil analisis pengaruh stres kerja terhadap turnover intention, diperoleh nilai koefisien beta sebesar 0,290 yang berarti adanya arah yang positif serta nilai signifikansi sebesar 0,000 yang kurang dari 0,05 berarti adanya pengaruh yang signifikan. Hasil ini mengindikasikan bahwa $\mathrm{H}_{0}$ ditolak dan $\mathrm{H}_{1}$ diterima sehingga stres kerja berpengaruh positif dan signifikan terhadap turnover intention.

Berdasarkan hasil analisis pengaruh stres kerja terhadap komitmen organisasional, diperoleh nilai koefisien beta sebesar -0,373 yang berarti adanya arah yang negatif serta nilai signifikansi sebesar 0,008 yang kurang dari 0,05 berarti adanya pengaruh yang signifikan. Hasil ini mengindikasikan bahwa $\mathrm{H}_{0}$ ditolak dan $\mathrm{H}_{2}$ diterima sehingga stres kerja berpengaruh negatif dan signifikan terhadap komitmen organisasional. 
Berdasarkan hasil analisis pengaruh komitmen organisasional terhadap turnover intention, diperoleh nilai koefisien beta sebesar -0,412 yang berarti adanya arah yang negatif serta nilai signifikansi sebesar 0,004 yang kurang dari 0,05 berarti adanya pengaruh yang signifikan. Hasil ini mengindikasikan bahwa $\mathrm{H}_{0}$ ditolak dan $\mathrm{H}_{3}$ diterima sehingga komitmen organisasional berpengaruh positif dan signifikan terhadap turnover intention.

Perhitungan pengaruh antar variabel dirangkum dalam Tabel 6.

Tabel 6.

Pengaruh Langsung Dan Pengaruh Tidak Langsung serta Pengaruh Total Stres kerja (X), Komitmen organisasional (M), dan Turnover intention (Y)

\begin{tabular}{cccc}
\hline Pengaruh Variabel & $\begin{array}{c}\text { Pengaruh } \\
\text { Langsung }\end{array}$ & $\begin{array}{c}\text { Pengaruh Tidak Langsung } \\
\text { Melalui Komitmen } \\
\text { Organisasional } \\
\left(\boldsymbol{\beta}_{\mathbf{2}} \mathbf{~} \boldsymbol{\beta}_{\mathbf{3}}\right)\end{array}$ & Pengaruh Total \\
\hline $\mathrm{X} \rightarrow \mathrm{Y}$ & 0,290 & 0,154 & 0,444 \\
$\mathrm{X} \rightarrow \mathrm{M}$ & $-0,373$ & - & $-0,373$ \\
$\mathrm{M} \rightarrow \mathrm{Y}$ & $-0,412$ & - & $-0,412$ \\
\hline
\end{tabular}

Sumber:Data diolah, 2018

Berdasarkan Tabel 5, dapat dilihat bahwa stres kerja memiliki pengaruh langsung terhadap turnover intention dan pengaruh tidak langsung melalui komitmen organisasional. Besarnya koefisien pengaruh tidak langsung dapat dihitung dengan mengalikan koefisien jalur dari stres kerja ke komitmen organisasional dengan koefisien jalur dari komitmen organisasional ke turnover intention sebesar $-0,373 \times-0,412=0,154$. Hasil koefisien pengaruh tidak langsung lebih kecil dibandingkan pengaruh langsung $(0,154<0,290)$, sehingga dapat dikatakan bahwa variabel komitmen organisasional adalah sebagai variabel mediasi dalam memediasi pengaruh variabel stres kerja tehadap variabel turnover intention. 
Pengujian signifikansi dari hubungan tidak langsung antara variabel independen dengan variabel dependen yang dimediasi oleh variabel mediasi dapat menggunakan alat analisis yang disebut uji Sobel. Uji Sobel dirumuskan dengan persamaan berikut:

$$
Z=\frac{a}{\sqrt{b^{2} S_{a}^{2}+a^{2} S^{2}+S_{a}^{2} S^{2}}}
$$

Keterangan:

$\mathrm{S}_{\mathrm{a}} \quad=$ standar eror keofisien a

$\mathrm{S}_{\mathrm{b}} \quad=$ standar eror keofisien $\mathrm{b}$

a $\quad$ = koefisien jalur $\mathrm{X}$ terhadap $\mathrm{M}$

$\mathrm{b} \quad=$ koefisien jalur $\mathrm{M}$ terhadap $\mathrm{Y}$

$\mathrm{ab} \quad=$ hasil kali koefisien jalur X terhadap koefisien jalur M (a) dengan jalur M terhadap Y (b)

Setelah mendapatkan hasil $\mathrm{Z}$ hitung, selanjutnya dibandingkan dengan nilai $\mathrm{Z}$ tabel yaitu 1,96. Jika nilai $\mathrm{Z}$ hitung lebih besar dari $\mathrm{Z}$ tabel, maka kesimpulannya adalah terjadi pengaruh mediasi secara signifikan. Perhitungan Uji Sobel untuk pengaruh tidak langsung antara stres kerja terhadap turnover intention melalui komitmen organisasional dihitung sebagai berikut:

$$
\begin{aligned}
& Z=\frac{a}{\sqrt{\mathrm{b}^{2} \mathrm{~S}_{\mathrm{a}}^{2}+\mathrm{d}^{2} \mathrm{~S}^{2}+\mathrm{S}_{\mathrm{a}}^{2} \mathrm{~S}^{2}}} \\
& Z=\frac{(-0,4) \times(-0,3)}{\sqrt{(-0,3)^{2} \times 0,1^{2}+(-0,4)^{2} \times 0,0^{2}+0,1^{2} \times 0,0{ }^{2}}} \\
& Z=\frac{0,1}{0,0} \\
& Z=3,082
\end{aligned}
$$

Berdasarkan perhitungan, didapatkan nilai $\mathrm{Z}$ hitung sebesar 3,082 yang artinya lebih besar dari nilai $\mathrm{Z}$ tabel $(3,082>1,96)$. Hasil ini memiliki arti bahwa 
komitmen organisasional mampu memediasi pengaruh stres kerja terhadap turnover intention. Oleh karena itu, $\mathrm{H}_{4}$ yang menyatakan bahwa komitmen organisasional dapat memediasi pengaruh stres kerja terhadap turnover intention diterima.

Berdasarkan hasil pengujian hipotesis pertama, diperoleh nilai koefisien beta sebesar 0,290 dengan signifikansi sebesar 0,000. Nilai koefisien beta yang memiliki arah positif serta nilai signifikansi yang lebih kecil dari tingkat probabilitas 0,05 mengartikan bahwa $\mathrm{H}_{0}$ ditolak dan $\mathrm{H}_{1}$ diterima. Hasil dari pengujian ini adalah stres kerja berpengaruh positif dan signifikan terhadap turnover intention. Artinya, apabila stres kerja rendah maka turnover intention atau keinginan karyawan Queen's Tandoor Seminyak untuk meninggalkan perusahaan akan semakin rendah. Sebaliknya, jika stres kerja tinggi maka turnover intention karyawan Queen's Tandoor Seminyak akan meningkat.

Hasil penelitian ini memperkuat beberapa penelitian sebelumnya yang telah membuktikan bahwa stres kerja berpengaruh positif dan signifikan terhadap turnover intention seperti yang dilakukan Rai (2015) yang menyimpulkan bahwa ketika karyawan memiliki tingkat stres kerja yang semakin tinggi maka intensi keluar dari perusahaan juga akan semakin meningkat. Begitu juga penelitian yang dilakukan Siddiqui and Jamil (2015), Ketabchi and Hazraty (2015), Manurung dan Ratnawati (2012), serta Parvaiz et al. (2015).

Berdasarkan hasil pengujian hipotesis kedua, diperoleh nilai koefisien beta sebesar -0,373 dengan signifikansi sebesar 0,008. Nilai koefisien beta yang memiliki arah negatif serta nilai signifikansi yang lebih kecil dari tingkat 
probabilitas 0,05 mengartikan bahwa $\mathrm{H}_{0}$ ditolak dan $\mathrm{H}_{2}$ diterima. Hasil dari pengujian ini adalah stres kerja berpengaruh negatif dan signifikan terhadap komitmen organisasional. Artinya, apabila stres kerja rendah maka tingkat komitmen organisasional yang dimiliki para karyawan Queen's Tandoor Seminyak akan semakin tinggi. Sebaliknya, jika stres kerja tinggi maka komitmen organisasional para karyawan Queen's Tandoor Seminyak akan semakin rendah.

Hasil penelitian ini sejalan dengan beberapa penelitian sebelumnya yang telah membuktikan bahwa stres kerja berpengaruh negatif dan signifikan terhadap komitmen organisasionalseperti yang dilakukan Nursyamsi (2012:12) yang menyimpulkan bahwa semakin besar stres kerja akan berakibat pada kinerja dan komitmen organisasional yang menurun atau berkurang. Begitu juga penelitian yang dilakukan Firth et al. (2004), Velnampy dan Aravinthan (2013), Rismawan (2014), serta Irwanto dkk. (2016).

Berdasarkan hasil pengujian hipotesis ketiga, diperoleh nilai koefisien beta sebesar -0,412 dengan signifikansi sebesar 0,004. Nilai koefisien beta yang memiliki arah negatif serta nilai signifikansi yang lebih kecil dari tingkat probabilitas 0,05 mengartikan bahwa $\mathrm{H}_{0}$ ditolak dan $\mathrm{H}_{3}$ diterima. Hasil dari pengujian ini adalah komitmen organisasional berpengaruh negatif dan signifikan terhadap turnover intention. Artinya, apabila tingkat komitmen organisasional tinggi maka turnover intention atau keinginan karyawan Queen's Tandoor Seminyak untuk meninggalkan perusahaan akan semakin rendah. Sebaliknya, jika komitmen organisasional rendah maka tingkat turnover intention para karyawan Queen's Tandoor Seminyak akan semakin tinggi. 
Hasil penelitian ini memperkuat beberapa penelitian sebelumnya yang telah membuktikan bahwa komitmen organisasional berpengaruh negatif dan signifikan terhadap turnover intention seperti penelitian yang dilakukan Mahardika dan Artha (2014) yang menyimpulkan bahwa semakin tinggi tingkat komitmen organisasional yang dimiliki karyawan maka akan menyebabkan tingkat turnover intention akan semakin rendah. Hasil yang sama juga ditemukan oleh Matti (2014), Kumar et al. (2012), Qureshi (2013), Velnamphy et al. (2013), serta Johartono dan Widuri (2014).

Berdasarkan hasil pengujian hipotesis keempat, diperoleh hasil pengaruh tidak langsung stres kerja terhadap turnover intention melalui komitmen organisasional dengan koefisien yang lebih kecil dibandingkan pengaruh langsung yaitu $0,154<0,290$. Sementara itu, pengujian dengan uji Sobel menunjukkan bahwa nilai $\mathrm{Z}$ hitung sebesar 3,082 yang lebih besar dari Z tabel yaitu 1,96 sehingga $\mathrm{H}_{4}$ diterima. Hasil ini mengartikan bahwa komitmen organisasional mampu memediasi pengaruh stres kerja terhadap turnover intention. Oleh karena itu, dapat diinterpretasikan bahwa tingkat stres kerja karyawan Queen's Tandoor Seminyak yang rendah akan berdampak pada tingginya komitmen organisasional yang dimiliki karyawan sehingga turnover intentionatau keinginan karyawan Queen's Tandoor Seminyak untuk meninggalkan perusahaan akan semakin rendah. Hasil penelitian ini sesuai dengan penelitian sebelumnya yang dilakukan oleh Rismawan, dkk. (2014) serta Firth et al. (2004) yang menjelaskan bahwa komitmen organisasional mampu memediasi pengaruh stres kerja terhadap turnover intention. 
Hasil dan pembahasan penelitian ini memberikan implikasi kepada restoran Queen's Tandoor Seminyak mengenai bagaimana stres kerja dan komitmen organisasional dapat memengaruhi turnover intention pada karyawannya. Penelitian ini menggunakan pendekatan stres kerja dan komitmen organisasional yang merupakan pengaruh langsung dari turnover intention. Stres kerja terbukti secara positif mempengaruhi turnover intention, oleh karena itu penting bagi manajemen Queen's Tandoor Seminyak untuk selalu memperhatikan faktor-faktor yang menyebabkan stres kerja karyawan di tempat kerja serta merangkul dan mengevaluasi para karyawan dengan tingkat stres kerja yang tinggi agar tidak tertekan dalam menghadapi pekerjaan. Hal tersebut demi membuat turnover intention yang disebabkan stres kerja dapat lebih rendah. Stres kerja terbukti secara negatif mempengaruhi komitmen organisasional, sehingga kembali lagi pentingnya memperhatikan hal-hal yang berdampak pada stres kerja agar karyawan Queen's Tandoor Seminyak merasa lebih berkomitmen pada perusahaan.

Komitmen organisasional terbukti secara negatif mempengaruhi turnover intention, oleh karena itu perhatian terhadap faktor-faktor yang mempengaruhi komitmen organisasional karyawan pada organisasi hendaknya ditingkatkan. Ketika karyawan Queen's Tandoor Seminyak berkomitmen tinggi pada perusahaan maka mereka akan memberikan lebih banyak upaya dalam bekerja demi meraih tujuan bersama, sehingga keinginan untuk keluar dari perusahaan akan semakin rendah. Keterkaitan antara stres kerja, komitmen organisasional, dan turnover intention bisa dijadikan pertimbangan bagi perusahaan lainnya 
dalam keputusan menyangkut sumber daya manusia demi terciptanya operasional perusahaan yang lebih baik.

\section{SIMPULAN DAN SARAN}

Berdasarkan pada hasil serta pembahasan penelitian yang telah dipaparkan, maka dapat disimpulkan bahwa stres kerja berpengaruh secara positif dan signifikan terhadap turnover intention. Hasil ini menunjukkan bahwa apabila stres kerja rendah, maka turnover intention atau keinginan karyawan Queen's Tandoor Seminyak untuk meninggalkan perusahaan akan semakin rendah. Sebaliknya, jika stres kerja tinggi maka turnover intention karyawan Queen's Tandoor Seminyak akan meningkat.

Stres kerja berpengaruh secara negatif dan signifikan terhadap komitmen organisasional. Hasil ini menunjukkan bahwa apabila stres kerja rendah maka tingkat komitmen organisasional yang dimiliki para karyawan Queen's Tandoor Seminyak akan semakin tinggi. Sebaliknya, jika stres kerja tinggi maka komitmen organisasional para karyawan Queen's Tandoor Seminyak akan semakin rendah.

Komitmen organisasional berpengaruh secara negatif dan signifikan terhadap turnover intention. Hasil ini menunjukkan bahwa apabila tingkat komitmen organisasional tinggi maka turnover intention atau keinginan karyawan Queen's Tandoor Seminyak untuk meninggalkan perusahaan akan semakin rendah. Sebaliknya, jika komitmen organisasional rendah maka tingkat turnover intention para karyawan Queen's Tandoor Seminyak akan semakin tinggi.

Komitmen organisasional mampu memediasi pengaruh stres kerja terhadap turnover intention. Hasil ini menunjukkan bahwa tingkat stres kerja karyawan 
Queen's Tandoor Seminyak yang rendah akan berdampak pada tingginya komitmen organisasional yang dimiliki karyawan sehingga turnover intention atau keinginan karyawan Queen's Tandoor Seminyak untuk meninggalkan perusahaan akan semakin rendah.

Berdasarkan hasil analisis, pembahasan, dan simpulan, maka saran yang dapat diberikan adalah manajemen Queen's Tandoor Seminyak hendaknya selalu memperhatikan faktor yang menyebabkan stres kerja karyawan di tempat kerja seperti mengurangi pemberian beban pekerjaan yang diluar kemampuan karyawan atau terlalu banyak yang mengakibatkan karyawan merasa terbebani, serta merangkul dan mengevaluasi para karyawan dengan tingkat stres kerja yang tinggi agar tidak tertekan dalam menghadapi pekerjaan. Hal tersebut demi meningkatkan komitmen organisasional karyawan dan membuat turnover intention yang disebabkan stres kerja dapat lebih rendah, sehingga karyawan Queen's Tandoor Seminyak lebih berkomitmen pada organisasi serta tidak berkeinginan untuk meninggalkan perusahaan.

Peningkatan perhatian pada faktor yang mempengaruhi komitmen organisasional karyawan menjadi penting, meningkatkan keterlibatan karyawan di dalam perusahaan agar karyawan dapat merasa bahwa perusahaan layak mendapatkan kesetiaan dari karyawan tersebut, karena ketika para karyawan Queen's Tandoor Seminyak berkomitmen tinggi pada perusahaan, maka mereka akan memberikan lebih banyak upaya dalam bekerja demi meraih tujuan bersama sehingga keinginan untuk keluar dari perusahaan akan semakin rendah. 
Peneliti selanjutnya diharapkan untuk melakukan penelitian dengan cakupan yang lebih luas, menambah variabel-variabel lain seperti kepuasan kerja, buaya organisasi, iklim oranisasi, dan kepemimpinan, serta kesehatan dan keselamatan kerja sehingga dapat memperluas pengetahuan.

\section{REFERENSI}

Abdullah, R. B., Musa, M., Zahari, H., Rahman, R., dan Khalid. (2012). The Effects of Teamwork towards Jobs satisfaction in Hotel Industry in Klang Valley, Malaysia. International Journal of Bussines and Behavioral Sciences, 2(3): 8-19.

Budiyono, R. (2016). Analisis Pengaruh Kepuasan Kerja, Stress Kerja, Dan Komitmen Organisasi Terhadap Turnover Intention (Studi Pada Pt. Duta Service Semarang). Journal Stie Semarang, 8(1): 37-53.

Chandio, J. A., Jhatial, A. A., dan Mallah, R. (2013). Modeling The Relationship Of Unclear Career Development With Jib Dissatisfaction, Job Stress and Employees Turnover Intention: Structural Equation Modeling Approach. Journal of Arts Humamanities, 41(41): 55-57.

Crow, M. M., Lee, C., and Joo, J. (2012). Organizational Justice and Organizational Commitmen aiming South Korean Police Officers: an Investigation of Job Satisfaction as a mediator. An International Journal of Public Strategies dan Management, 34(2): 402-423.

Fah, C. B., Foon, S. Y., Leong, C., and Osman, S. (2010). An Exploratory Study on Turnover Intention among Private Sector Employees. International Journal of Business and Management, 5(8): 57-64.

Faslah, R., Hairiah, L. (2017). The Influence of Job Involement and Job Satisfaction Toward Turnover Intention on Employees of PT. Global Nikel Multiguna Tangerang. Jurnal Ilmiah Econosains, 15(1): 140-165.

Firth, L., Mellor, D. J., Moore, K. A., Loquet, C. 2004. How can Managers Reduce Employee Intention to quit?.Journal of Managerial Psychology, 19(2): 170-187.

Green, A. E., Miller, E. A., and Aarons, G. A. (2013). Transformational Leadership moderators the relationship between emotional exhaustion and turnover intention among community mental health provider. Community Mental Health Journal, 49 (4): 373-379. 
Irwanto., Riana, I. G., Yasa, N. N. K. (2016). Peran Komitmen Organisasional Memediasi Pengaruh Stres Kerja dan Kepuasan Kerja Terhadap Intensi Keluar. E-Jurnal Ekonomi dan Bisnis Universitas Udayana, 5(9): 28912920.

Jehanzeb, K., Rasheed, A., and Rasheed, M. F. (2013). Organizational Commitment and Turnover Intentions: Impact of Employee's Training in Private Sector of Saudi Arabia. International Journal Of Business\& Management, 8(8): 79-90.

Jha, S. (2010). Determinant of Employee Turnover Intentions: A Review. Indian Lecture Review, 1 (1): 1-22.

Johartono dan Widuri, R. (2014). Analisa Pengaruh Stres kerja, Kepuasan Kerja, Budaya Organisasi dan Komitmen Organisasi Terhadap Turnover intention karywan Kantor Konsultan pajak di Surabaya. Journal of Tax and Accounting Review, 3(2): 223-241.

Ketabchi, H., and Hazraty, M. (2015). Examining the Relationship between Job Stress and Turnover Tendency with Mediating Role of Job Satisfaction among the Employees of Alzahra Hospital in Rasht. Jurnal UMP Social Sciences and Technology Management, 3 (3): 842-846.

Khan, M. S., Kundi, G. M., Khan, S., Khan, I., Khan, H., and Yar, N. B. (2014). The cause\&effect and correlation between Job Satisfaction and Organizational Commitment on Intention to leave among the Academicians in Higher Educational Institutions of Khyber Pakistan. International Journal of Academic Research in Bussiness and Social Sciences, 4(2): 2222-6990.

Kumar, R., Ramendran, C., and Yacob, P. (2012). A Study on Turnover Intention in Fast Food Industry: Employees' Fit to the Organizational Culture and the Important of their Commitment. International Journal of Academic Research in Business and Social Sciences, 2(5): 9-42.

Lum, L., Kervin, J., Clark, K., Reid, F., and Sirola, W. 1998. Explaning Nursing Turnover Intent: Job Satisfaction, Pay Satisfaction, or Organizational Commitment. Journal of Organizatioal Behavior, 19 (3): 305-320.

Manurung, T. M., dan Ratnawati, I. (2012). Analisis Pengaruh Stres Kerja dan Kepuasan Kerja Terhadap Turnover Intention Karyawan (Studi Pada Stikes Widya Husada Semarang). Diponegoro Journal Of Management, 1(2): 145157.

Matti, V. (2014). Organizational reform in hierarchical frontline organization tracking changes in stress and turnover intention during finish police reform years. An International Journal of Police Strategies \& Management, 37(4): 850-874. 
Nursyamsi, I. (2012). Pengaruh Kepemimpinan, Pemberdayaan, dan Stres Kerja Terhadap Komitmen Organisasional serta dampaknya terhadap Kinerja Dosen. Conference in Business, Accounting, and Management (CBAM). Universitas Islam Sultan Agung (Unissula) Semarang 6-7 Desember (2012): $1-16$.

Paille, P. (2011). Stressful Work, Citizenship Behaviour and Intention to Leave the Organization in a High Turnover Environment: Examining the Mediating Role of Job Satisfaction. Journal of Management Research, 3(1): $1-14$

Parvaiz, L., Saba, B., Ambar, K., and Yasir, A. F. (2015). Impact Of Stressors (Role Conflict, Role Overload, Leadership Support and Organizational Politics) On Job Stress and Its Subsequent Impact On Turnover Intention. International Journal of Business and Management Invention, 4(10): 52-63.

Putra, E. M., Wibawa, M. A. (2014). Pengaruh Kepuasan Kerja Terhadap Turnover Intention dengan Komitmen Organisasi sebagai variable Intervening pada PT. Auto Bagus Rent Car Bali. E-Jurnal Manajemen Unud, 4(4): 1100-1118.

Qureshi, M. I. (2013). Relationship Between Job Stress, Workload, Environment and Employees Turnover Intention: What We Know, What Should We Know. World Applied Sciences Journal, 23(6): 764-770.

Rai, G. S. (2015). Turnover Intention among Long-term Care Staff: Three Possible Culprits. International Journal of Business and Social Science, 6 (8): 1-9.

Rismawan, P. A. E., Supartha, W. G., Yasa, N. N. K. (2014). Peran Mediasi Komitmen Organisasional pada Pengaruh Stres Kerja dan Kepuasan Kerja terhadap Intensi Keluar Karyawan. E-Jurnal Ekonomi dan Bisnis Universitas Udayana, 8(3): 424-441.

Robbins, S. P., dan Judge, T. A. (2015). Perilaku Organisasi. Edisi ke 16. Terjemahan Oleh Ratna Saraswati dan Febriela Sirait. Jakarta: Salemba Empat.

Saqib, M. K., Kundi, G. M., Shadiullah, K., Irfanullah, K., Hamid, K., and Naseem, B. Y. (2014). The Cause \& Effect and Correlation between Job Satisfaction and Organizational Commitment on Intention to leave among the Academicians in higher Educational Institutions of Khyber Pakhtunkhwa, Pakistan. International Journal of Academic Research in Business and Social Sciences. 4(2): 2222-6990.

Siagian, S. P. (2012). Manajemen Sumber Daya Manusia. Jakarta: Bumi Aksara. 
Siddiqui, A. A., and Jamil, R. A. (2015). Antecedents of Employees' Turnover Intentions: Evidence from Private Educational Institutions. American Journal of Economics and Business Administration, 7 (4): 160-165.

Sidharta, N. \& Margaretha, M. (2011). Dampak Komitmen Organisasi dan Kepuasan Kerjaterhadap Turnover Intention: Studi Empiris Pada Karyawan Bagian Operator di Salah Satu Perusahaan Garment di Cimahi. Jurnal Manajemen, 10(2): 129-142.

Tania, A., dan Sutanto, E. M. (2013). Pengaruh motivasi kerja dan kepuasan kerja terhadap komitmen organisasional karyawan PT. Dai Knife di Surabaya. Agora, 1(3): 1-9.

Udayana, I. G. A. P., dan Dewi, I. G. A. M. (2017). Pengaruh Stres Kerja Dan Komitmen Organisasional Terhadap Turnover Intention Di Simpang Inn Hotel Kuta. E-Jurnal Manajemen Unud, 6(12): 6734-6762.

Velnampy, T., and Aravinthan, S. A. (2013). Occupational Stress and Organizational Commitment in Private Banks: A Sri Lankan Experience. European Journal of Business and Management, 5(7): 78-99.

Widodo, S. E. (2015). Manajemen Pengembangan Sumber Daya Manusia. Yogyakarta. Pustaka Pelajar. 